\title{
Kinetics of Biodiesel Production from Soya Bean Soap Stock
}

\author{
Chinedu Gabriel Mbah ${ }^{1, *}$, Chizoo Esonye ${ }^{2}$, Dominic Okechukwu Onukwuli \\ ${ }^{1}$ Department of Chemical Engineering, Federal Polytechnic, Oko, Nigeria \\ ${ }^{2}$ Department of Chemical and Petroleum Engineering, Alex Ekwueme Federal University, Ndufu Alike Ikwo, Nigeria \\ ${ }^{3}$ Department of Chemical Engineering, Nnamdi Azikiwe University, Awka, Nigeria
}

Email address:

gadoral@yahoo.com (C. G. Mbah)

${ }^{*}$ Corresponding author

\section{To cite this article:}

Chinedu Gabriel Mbah, Chizoo Esonye, Dominic Okechukwu Onukwuli. Kinetics of Biodiesel Production from Soya Bean Soap Stock. Earth Sciences. Vol. 10, No. 5, 2021, pp. 198-206. doi: 10.11648/j.earth.20211005.11

Received: August 11, 2021; Accepted: August 23, 2021; Published: September 7, 2021

\begin{abstract}
Low quality lipids such as soyabeanrsoapstock, a by-product of vegetable oil processing can be used as a viable feedstock for the production of biodiesel due to its high yield capacity, availability, and low cost. Sodium hydroxide and methanol were used as catalyst and solvent respectively while $\mathrm{n}$-hexane was added as a co-solvent. Kinetics of the transesterification reaction mechanismfor soyabeansoapstock with and without co-solvent (n-hexane) was carried out using models proposed by Singh \& Fernando, (2007) to determine the reaction order and rate constant at different temperatures $\left(45^{\circ} \mathrm{C}, 55^{\circ} \mathrm{C}\right.$ and $\left.65^{\circ} \mathrm{C}\right)$. Similar rate constants were obtained (with and without co-solvent) though with slightly different $\mathrm{R}^{2}$ values showing that $n$-hexane does not distort the chemistry of the reaction. Negative and very low $\mathrm{R}^{2}$ values obtained at temperatures $45^{\circ} \mathrm{C}$ and $65^{\circ} \mathrm{C}$ further affirms $55^{\circ} \mathrm{C}$ as the optimum temperature for the reaction. An activation energy of 74 $\mathrm{KJ} / \mathrm{mol}$ and frequency factor of 2.9 was also obtained. Findings from the studyshows that soyabeansoapstock is a viable feedstock for the production of biodiesel and n-hexane was a suitable co-solvent in the transesterification of low quality lipids (soyabean soap stock). A rate constant of $0.0008 \mathrm{~min}^{-1}$ and reaction order of 2 was obtained for the transesterification reaction.
\end{abstract}

Keywords: Biodiesel, Kinetics, Rate Constant, Soyabeansoapstock

\section{Introduction}

Biodiesel are fuels composed of mono-alkyl esters of long chainfatty acids. The long and branched chain triglyceride molecules are transformed into mono-alkyl esters and glycerol through esterification/transesterification reactions [10]. Biodiesel can be prepared from abundant vegetable oils, animal fats, or microalgae oil by the transesterification of triglycerides (TG) with methanol using an alkaline, acid or enzyme catalysts [12]. Transesterification of vegetable oils can be carried out usingboth homogeneous (acid or base) and heterogeneous (acid, baseand enzymatic) catalysts [18]. Homogeneous base catalysts providemuch faster reaction rates than heterogeneous catalysts in thetransesterification of oilsthough the catalysts dissolve fully inthe glycerin layer and partially in the biodiesel, which makes theproduct separation and purification process a tedious one [15].
Transesterification is performed commonly using a base catalyst, such as sodium hydroxide and potassium hydroxide $(\mathrm{NaOH}, \mathrm{KOH})$, and alcohols such as methanol due to their low prices, effectiveness, low concentration, and heat requirements in the reaction [11]. The rate of transesterification mainlydepends on the free fatty acid (FFA) composition of the oil andthe type of catalyst chosen $[1,8]$. Factors that affect transesterification reactions include mass transfer limitations, low reaction rate due to the biphasic system of oil/methanol mixture and difficulty in product purification (i.e removing impurities such as soaps, residual catalysts, methanol traces, glycerol and water) [7].

Atwo-step transesterification (acid esterification followed by alkalitransesterification) process [9] and increase in molar ratios ofmethanol to oil are sometimesrequired to drive the reaction towards completion for high FFA bearing oils [13]. Addition of suitable compounds such as n-hexane, benzene, tetrahydrofuran (THF) and ionic liquids has also 
beenintroduced as co-solvents to improve the miscibility of oil and methanol and to enhance the catalyst activity [12]. This has greatly improved biodiesel production efficiencyespecially in cases where the two aforementioned solutions failed to give the required biodiesel quality and yield.

The kinetics of a process describes the rate of the chemical reaction. Rate equations are typically written in terms of the concentration of the reactants [17]. In the past, it has been observed that the base catalyzed transesterification is a second order reaction [3]. This has been confirmed in a different study for the transesterification of soybean oil with methanol using sodium hydroxide as a homogeneous catalyst [14].

This paper however seeks to establish the viability of using soya bean soap stock (a low quality lipid) as a feedstock for biodiesel production and to verify the rate and order of the transesteification reaction.

\section{Materials and Methods}

\subsection{Reagents and Materials}

Methanol (Sigma-Aldrich), $\mathrm{NaOH}$ flakes, Phenopthalene, Sulphuric acid, Magnesium trisilicate $\left(\mathrm{MgSi}_{3}\right)$, Sodium Sulphate, n-hexane, Diethyl ether.

\subsection{Apparatus and Instruments}

Beakers (20ml, 50ml, 100ml), Centrifuge (Hettich University II), Conical Flasks (20ml, 50ml, 100ml, 1000ml), Cuvettes, Electronic Weighing Balance. (B. Bran Scientific, England), Heat drying oven (DHG Series Ocean $\mathrm{Med}^{+}$ England), Electronic Temperature Regulation Heating Mantle (98-I-B Series), HH-S Thermostatic water Bath (DKS Series; Ningbo Biocotek Scientific Instrument Co., Limited, Measuring Cylinder, Pipette (1ml, 2ml, 5ml, Pyrex), Test tubes (5ml, 10ml, Pyrex), Gas chromatography coupled FID and ECD, Buck Scientific Infra-red Spectrophotometer. Model (M530), Seperating Funnel.

\subsection{Sample Collection}

Contaminated soybean soapstock was obtained from Sunchi farms, an integrated poultry and feed processing plant in Enugu. The soyabeansoapstock a lipid-rich by-product produced during vegetable oil refining process was collected in a clean gallon. It was then put into a centrifuge. The centrifugation was operated for 7 minutes, at 3,000 rpm and $25^{\circ} \mathrm{C}$. It was separated into three layers after centrifugation. The top layer which is the acid oil (AO), otherwise known as the soapstock was collected for use. The middle and bottom layer which are emulsified materials containing lipids, salts and water were discarded.

\subsection{Characterisation of SoyabeanSoapstock}

\subsubsection{Preparing Soyabeansoapstock for Gas Chromatography Analysis}

$1 \mathrm{~g}$ of magnesium trisilicate $\left(\mathrm{MgSi}_{3}\right)$ and $0.5 \mathrm{~g}$ of sodium sulphate was mixed in a separating funnel, 1-2 $\mathrm{ml}$ of sample and $10 \mathrm{ml}$ of $\mathrm{n}$-hexane was added to the solution and allowed to settle, the n-hexane was collected for analysis.

\subsubsection{Gas Chromatography Analysis}

The fatty acid composition of the soyabeansoapstock was analyzed by gas chromatography and mass spectrometer according to AOCS official method Ce 2-66. The gas chromatographic analysis was made usingGC-MS-QP2010 plus, Shimadzu. The GC column used was calibrated using methyl ester standards [5]. Good seperations were achieved by diluting the samples ( $\mathrm{n}$-hexane collected) in a small amount of ethyl acetate. The carrier gas used was hydrogen and its flow rate was regulated at $41.27 \mathrm{ml} / \mathrm{mins}$ while the column flows at $1.82 \mathrm{ml} / \mathrm{mins}$. The oven temperature was set at $80^{\circ} \mathrm{C}$ before rising up at $6^{\circ} \mathrm{C} / \mathrm{min}$ until $340^{\circ} \mathrm{C}$. The identification of peaks was done by comparison of their retention time and mass spectra with mass spectra library (NIST05s LIB) [5]. The gas chromatography analysis was carried out for both the sample and produced methyl ester.

\subsection{Biodiesel Production from SoyabeanSoapstock}

\section{Esterifiation of Soybean Soapstock}

Equal volume of Soybean soapstock and alcohol (methanol) was mixed in a beaker, Sulphuric acid in the ratio of 1:10 to the solution was added, the solution was then heated and stirred over varied temperatures, time and speed. The Solution was then separated in a separating funnel.

Transesterification of esterified oil $30 \mathrm{ml}$ of sample was mixed with methanol and n-hexane in the ratio of $1: 3: 3$ respectively. $2 \% \mathrm{NaOH}$ catalyst was added and stirred. Temperature, speed and time were also varied. The solution was poured into a separating funnel, washed with hot water and the biodiesel separated.

The transesterification reaction is represented in equation 1 below.

$$
A+3 B=C+D
$$

where $A$ is the triglyceride, $B$ is methanol, $C$ is FAME and $D$ is glycerol [5].

\subsection{Kinetics of Transesterification Reaction}

The overall triglyceride transesterification reaction is reversible and excess amount of alcohol is used to shift the equilibrium towards the formation of esters.

The general rate equation for the Equation (1) above is:

$$
\frac{-d C A}{d t}=k C_{A}^{\alpha} C_{B}^{\beta}
$$

where $-C_{A} / t$ is the consumption of reactant $A$ per unit time, $k$ is a rate constant, $C_{\mathrm{A}}$ is the concentration of $A$ after time $t, C_{\mathrm{B}}$ is the concentration of $B$ after time $t, a$ is the order of reactant $A$, and $\beta$ is the order of reactant $B$ [17].

In addition:

$$
\begin{array}{r}
C_{A}=C_{A 0}(1-X) \\
C_{B}=C_{A 0}(\theta B-3 X)
\end{array}
$$




$$
\theta B=\frac{C_{B 0}}{C_{A 0}}
$$

where $C_{\mathrm{A} 0}$ is the initial concentration of $A, C_{\mathrm{B} 0}$ is the initial concentration of $B$,

$X$ is the conversion, and $\theta \mathrm{B}$ is the ratio of $C_{\mathrm{B} 0}$ to $C_{\mathrm{A} 0}$. Eq. (2) can be written as:

$$
\frac{d X}{d t}=K C_{A 0}^{(\alpha+\beta-1)}(1-X)^{\alpha}(\theta B-3 X)^{\beta}
$$

In the present work, eight different cases were analyzed in order to obtain the reaction order. These cases were $(\alpha=0, \beta=$ $0),(\alpha=1, \beta=0),(\alpha=0, \beta=1),(\alpha=1, \beta=1),(\alpha=2, \beta=0)$,

$$
(\alpha=0, \beta=2),(\alpha=2, \beta=1) \text { and }(\alpha=1, \beta=2) \text {. }
$$

For each case, definite integrals of Eq. (6) were calculated from a conversion of $X=0$ to a conversion of $X=X$ in the time span of $t=0$ to $t=t$. The calculated equation for eachcase was then transferred into a linear equation passing through origin $(y$ $=m x$ ) [17]. The transferred equations thus became models for kinetic studies and with each of the eight cases represented by a model as illustrated in equations 6 to 13 below:

$$
\begin{gathered}
\text { Case } 1:(\alpha=0, \beta=0): C_{A 0} X=k t \\
\text { Case } 2:(\alpha=1, \beta=0): \ln (1 / 1-X)=k t
\end{gathered}
$$

Case 3: $(\alpha=0, \beta=1):-\frac{1}{3}[\ln (\theta B-3 X) / \theta B]=k t$

$$
\text { Case 5: }(\alpha=2, \beta=0): X /(1-X)=k C_{A 0} t
$$

$$
\text { Case 6: }(\alpha=0, \beta=2): X /(\theta B-3 X) \theta B=k C_{A 0} t
$$

$$
\text { Case 7: }(\alpha=2, \beta=1): \frac{1}{(\theta B-3)}\left\{X /(1-X)-3 /(\theta B-3) \ln \left[\frac{(\theta B-3 X)}{(1-X) \theta B}\right]\right\}=k C_{A 0}^{2} t
$$

$$
\text { Case 8: }(\alpha=1, \beta=2): \frac{1}{(3-\theta B)}\left\{3 X /(\theta B-3 X) \theta B-1 /(3-\theta B) \ln \left[\frac{(1-X) \theta B}{(\theta B-3 X)}\right]\right\}=k C_{A 0}^{2} t
$$

In model equations $(7-14)$, it is assumed that the left-side component is an ordinate ( $y$ variable). The $\mathrm{x}$ variables are represented on the right side of the model equationswhicharet, (for models equations. $(7-9)$ ), $C_{\mathrm{A} 0} t$ (for model equations. (10-12) and $C_{\mathrm{A} 0}^{2} t$ (for model equations. (13) and (14) respectively, the model equations are in the form of $y=m x$ (a straight line passing through origin). For all eight models, the $y$ variable was plotted against the corresponding $x$ variable and the coefficient of determination was estimated. In all cases for Equations (7-14), the slope of the straight line is the rate constant, $k$, for the reaction. The highest correlation coefficient, $R^{2}$, for each case was observed and the case that gave the highest correlation coefficient was used to determine the reaction order [6].

\section{Results and Discussion}

\subsection{Effect of $N$-hexane on Reaction Kinetics}

Plots from the eight (8) kinetic models (equations 7-14) proposed by Singh \& Fernando, [17] were used to determine the order and rate of the transesterification reactions of soyabeansoapstock with n-hexane and without n-hexane (cosolvent). In all cases for the models by Singh \& Fernando, the slope of the straight line is the rate constant, $\mathrm{k}$, for the reaction. The highest correlation coefficient, $\mathrm{R}^{2}$, for each case was observed and the case that gave the highest correlation coefficient was used to determine the reaction order. It can be observed that the transesterification of soyabeansoapstock using n-hexane was favoured by model equation 10 (case 4) having the highest $\mathrm{R}^{2}$ value of 0.891 . This implies a rate constant of 60.0008 and an overall order of $2(1+1)$. It was observed from Table 1 below that the $\mathrm{R}^{2}$ values for reactions involvingn-hexane were generally lower than $R^{2}$ values obtained without using n-hexane. This could be because methanol, a colorless liquid is only slightly soluble in hexane. The molecules in methanol are however known to be polar and will readily dissolve in water but not in n-hexane. This thus explains the low $\mathrm{R}^{2}$ values obtained. An increase in temperature was seen to however improve the $\mathrm{R}^{2}$ values highlighting the effect of temperature on the miscibility of both solvents (methanol and n-hexane). The rate constants were however similar showing that the n-hexane neither affects the composition of the products or the rate of the reactions. The high yield obtained with the use of $n$-hexane at $55^{\circ} \mathrm{C}$ however informed its choice as the optimum process.

Table 1. Comparism of rate constants $(k)$ and $R^{2}$ values with and without $n$-hexane.

\begin{tabular}{llll}
\hline \multirow{2}{*}{ Models } & With n-hexane & Without n-hexane \\
\cline { 2 - 4 } & Rate constants (k) & $\mathbf{R}^{2}$ values & Rate constants (k) \\
\hline Case 1 & 0.1482 & -0.140 & 0.159 \\
Case 2 & 0.013 & 0.530 & 0.014 \\
Case 3 & 0.0072 & 0.787 & 0.007 \\
Case 4 & 0.008 & 0.891 & 0.0009 \\
Case 5 & 0.0013 & 0.863 & 0.921 \\
\hline
\end{tabular}




\begin{tabular}{lllll}
\hline \multirow{2}{*}{ Models } & With n-hexane & & Without $\mathbf{n}$-hexane & \\
\cline { 2 - 5 } & Rate constants $(\mathbf{k})$ & $\mathbf{R}^{2}$ values & Rate constants $(\mathbf{k})$ & $\mathbf{R}^{2}$ values \\
\hline Case 6 & 0.0005 & 0.781 & 0.00056 & 0.875 \\
Case 7 & 0.000001 & 0.886 & 0.000001 & 0.971 \\
Case 8 & 0.000008 & 0.858 & 0.00001 & 0.969 \\
\hline
\end{tabular}

Figures 1 and 2 below however shows the kinetic plots from which the rate constants $(\mathrm{K})$ and reaction orders were obtained from the transesterification of soyabeansoapstock with and without n-hexane.
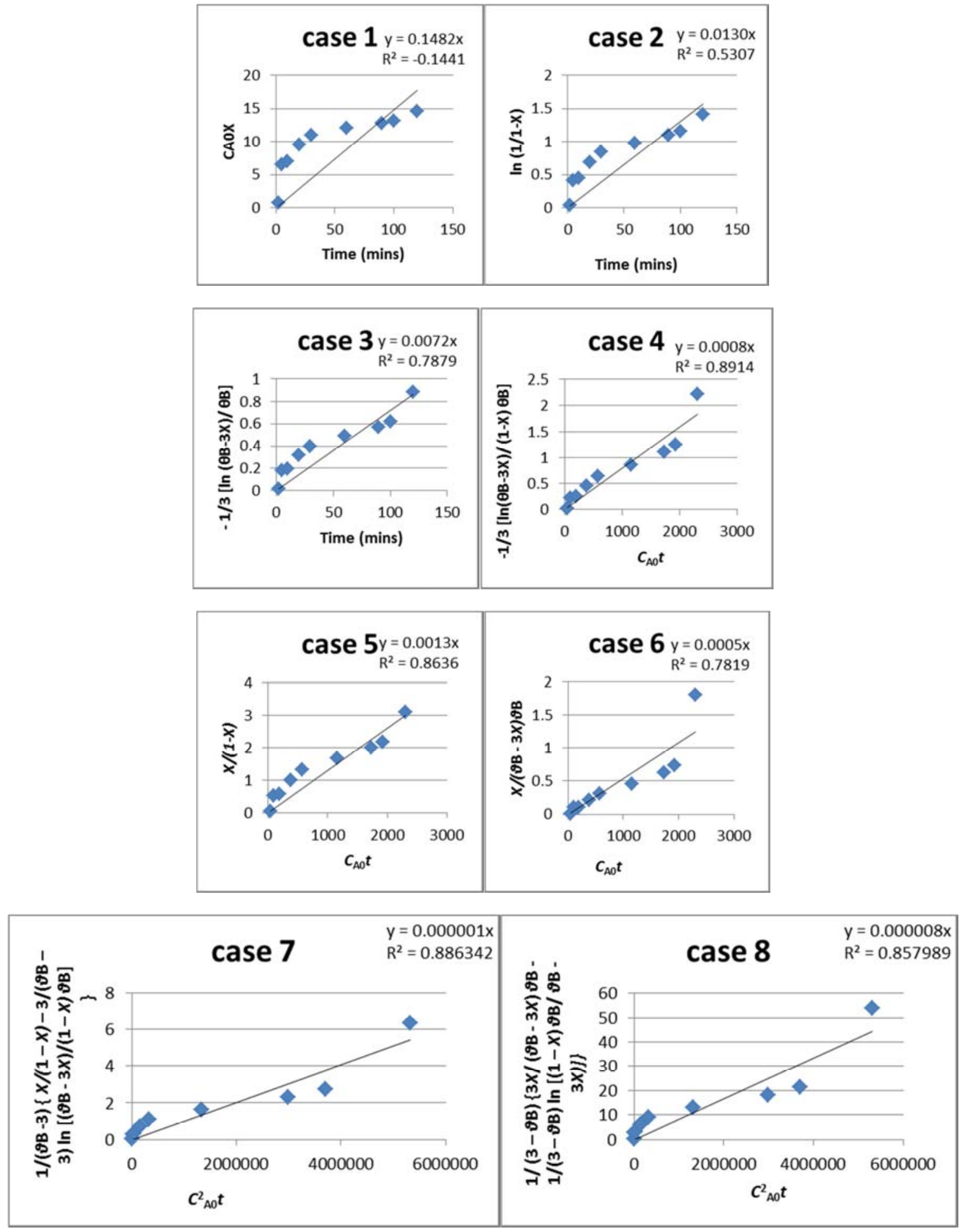

Figure 1. Transesterification kinetics plot of soyabeansoapstock using co-solvent (n-hexane). 

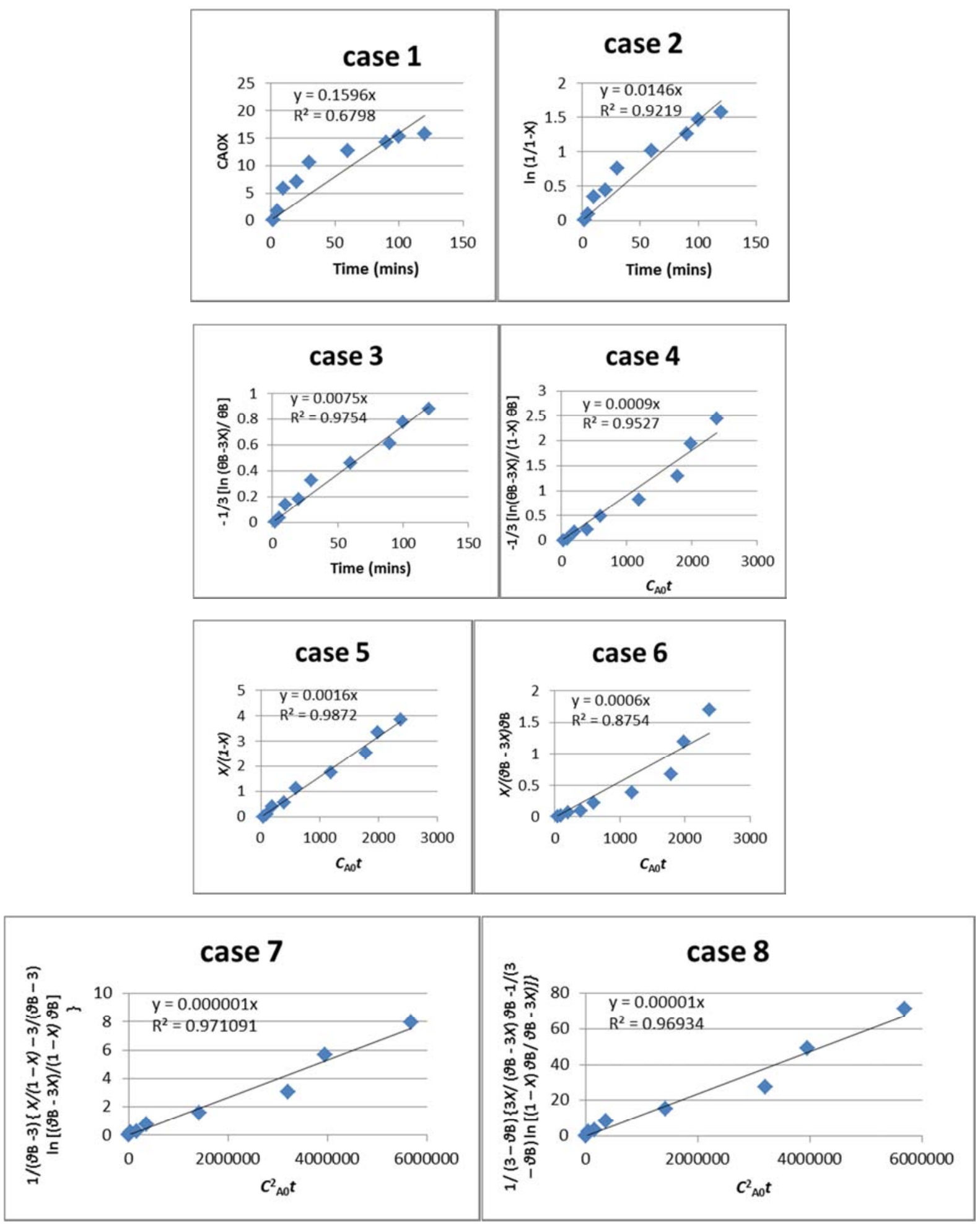

Figure 2. Kinetics plot for soyabeansoapstock without co-solvent (n-hexane).

\subsection{Effect of Different Temperatures on Reaction Kinetics}

It can be observed that the $\mathrm{R}^{2}$ values for transesterification at $45^{\circ} \mathrm{C}$ was much lower than $\mathrm{R}^{2}$ values at $55^{\circ} \mathrm{C}$ and $65^{\circ} \mathrm{C}$. The rate constants (slopes) were also in some cases insignificant (at $45^{\circ} \mathrm{C}$ ), this could be due to the reaction temperature at $45^{\circ} \mathrm{C}$ not being high enough to trigger and sustain the transesterification reaction. The $\mathrm{R}^{2}$ values at $55^{\circ} \mathrm{C}$ were marginally higher than at $65^{\circ} \mathrm{C}$ which is a higher temperature. This further affirms $55^{\circ} \mathrm{C}$ as the optimum temperature for transesterification of soyabeansoapstock. Table 2 below shows a comparism of rate constants $(\mathrm{K})$ and $\mathrm{R}^{2}$ valuesfor soyabeansoapstock biodiesel at $45^{\circ} \mathrm{C}, 55^{\circ} \mathrm{C}$ and $65^{\circ} \mathrm{C}$. It can be observed that $R^{2}$ values for all cases at $45^{\circ} \mathrm{C}$ were well below the required standard and thus transesterification at such temperature will not be ideal. The $\mathrm{R}^{2}$ values at $55^{\circ} \mathrm{C}$ and $65^{\circ} \mathrm{C}$ were however suitable enough and can 
be considered as viable temperatures for transesterification of soyabeansoapstock to produce biodiesel. At $55^{\circ} \mathrm{C}$, model "4" had the highest $\mathrm{R}^{2}$ values which translates to a reaction order of
$2(1+1)$ and a $0.891 \mathrm{~min}^{-1}$ rate constant. The highest $\mathrm{R}^{2}$ value at $65^{\circ} \mathrm{C}$ (model " 7 ") translated to a reaction order of $3(2+1)$ and rate constant of $0.0000004 \mathrm{~min}^{-1}$.

Table 2. Comparism of rate constants $(K)$ and $R^{2}$ values for soyabeansoapstocktransesterification at different temperatures.

\begin{tabular}{llllll}
\hline \multirow{2}{*}{ Models } & $\mathbf{4 5}^{\circ} \mathbf{C}$ & & $\mathbf{5 5}^{\circ} \mathbf{C}$ & \multicolumn{2}{c}{$\mathbf{6 5}^{\circ} \mathbf{C}$} \\
\cline { 2 - 6 } & Rate constants (k) & $\mathbf{R}^{\mathbf{2}}$ values & Rate constants (k) & $\mathbf{R}^{\mathbf{2}}$ values & Rate constants (k) \\
\hline Case 1 & 0.129 & -47 & 0.148 & -0.14 & 0.133 \\
Case 2 & 0.0095 & -20 & 0.0013 & 0.53 & 0.01 \\
Case 3 & 0.0044 & -14 & 0.0072 & 0.787 & 0.0049 \\
Case 4 & 0.0003 & -5.9 & 0.008 & 0.891 & 0.0004 \\
Case 5 & 0.0007 & -8.72 & 0.0013 & 0.863 & 0.0008 \\
Case 6 & 0.0002 & -3.95 & 0.0005 & 0.781 & 0.0002 \\
Case 7 & 0.0000003 & -4.62 & 0.000001 & 0.886 & 0.0000004 \\
Case 8 & 0.000002 & -6.84 & 0.000008 & 0.858 & 0.000004 \\
\hline
\end{tabular}
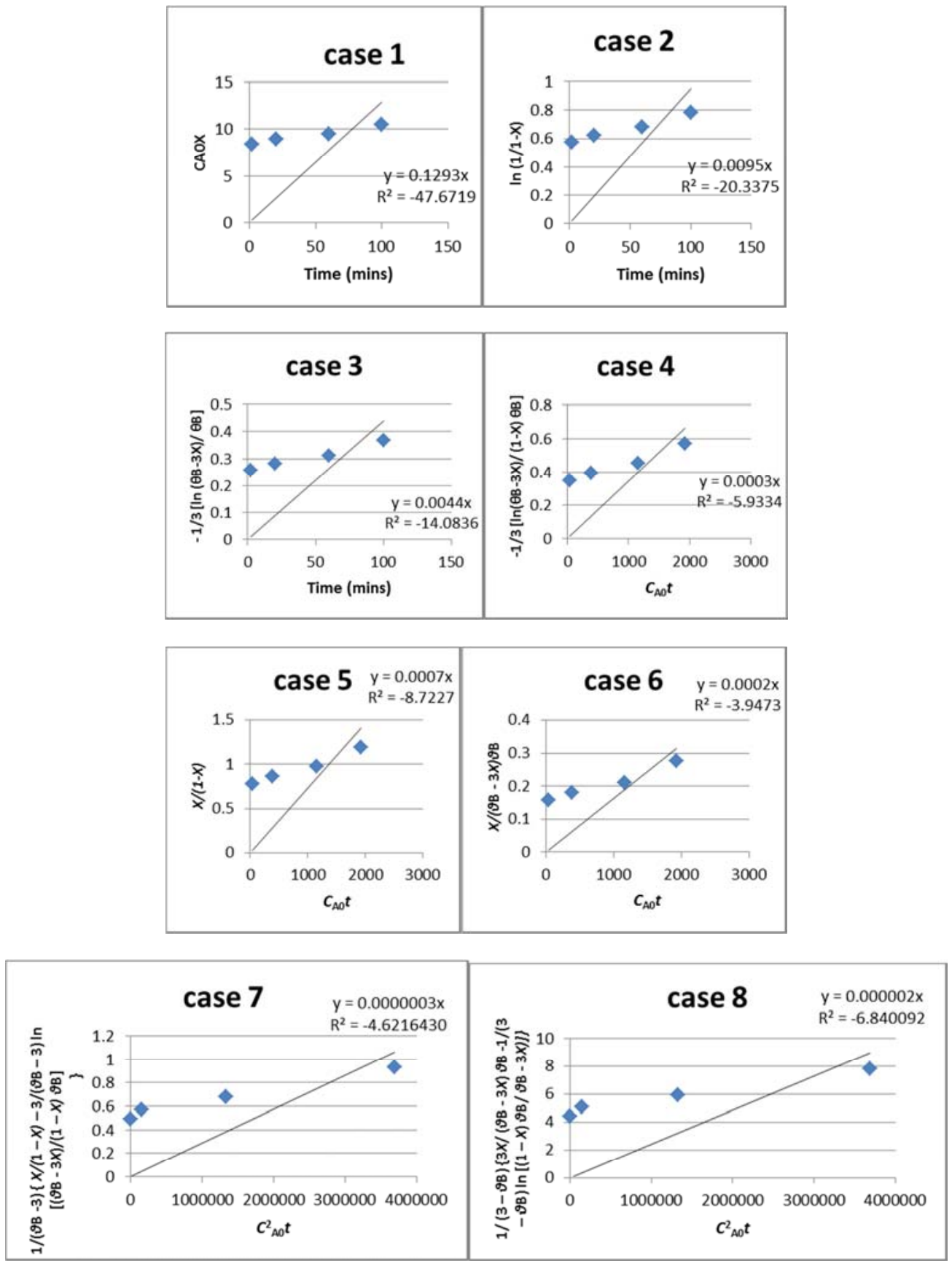

Figure 3. Kinetics plots for soyabeansoapstock transesterification with co-solvent at $45^{\circ} \mathrm{C}$. 

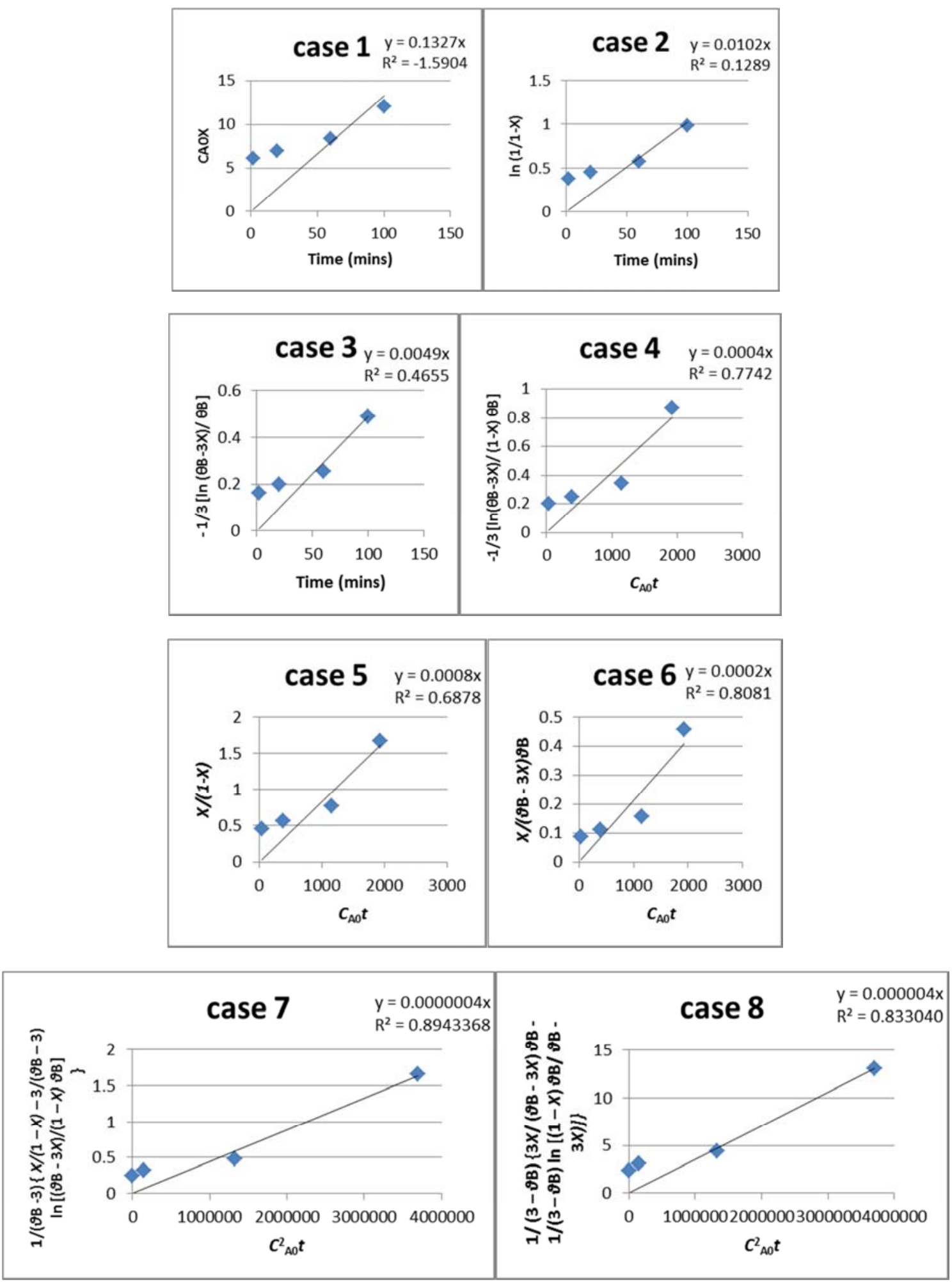

Figure 4. Kinetics plot for soyabeansoapstock transesterification with co-solvent at $65^{\circ} \mathrm{C}$.

Figures 3 and 4 below however shows the kinetic plots from which the rate constants $(\mathrm{K})$ and reaction orders were obtained from the transesterification of soyabeansoapstock at $45^{\circ} \mathrm{C}$ and $65^{\circ} \mathrm{C}$ respectively.

\subsection{Determination of Activation Energy}

The best-fit values of the rate constants were used for obtaining approximate activation energy for the reversible reaction process of the transesterification by looking for a linear regression relationship between the logarithm of the rate constants and the inverse of the absolutetemperature with high values of $\mathrm{R}^{2}$ for both forward and backward reactions. The slope was used for estimating activation energies using Arrhenius equation [6]. The relationship among the specific 
reaction rate constants $(\mathrm{K})$, absolute temperature $(\mathrm{T})$ and activation energy (Ea) is given by the Arrhenius equation.

$$
\mathrm{K}=A \exp \frac{-E a}{R T} .
$$

Where $\mathrm{A}=$ frequency factor, $\mathrm{R}=$ universal gas constant (8.314).

The linear regression of this equation gives the activation energy.

The activation energy of the forward transesterification reaction is $74.17 \mathrm{KJ} / \mathrm{mol}$. This is significantly higher than activation energy of biodiesels from less saturated oil feedstocks. Choudhury et al, [2] carried out synthesis of biodiesel from Jatrophacurcas with about $23.4 \%$ saturated fatty acids obtaining an activation energy of $57.33 \mathrm{KJ} / \mathrm{mol}$. Rapeseed oil recorded an even lower activation energy of $21.88 \mathrm{KJ} / \mathrm{mol}$ due to the relatively low volume of saturates $(6.6 \%)$. The higher volume of saturates in soyabeansoapstock (51\%) thus justifies the high activation energy needed. Reactions with high activation energy need a higher temperature and longer reaction time [4]. This thus justifies the higher reaction temperatures and time required in the transesterification of soyabeansoapstock compared to most other vegetable oils. Another factor which affects activation energy is the presence/nature of catalyst used in the reaction [4]. This can be observed from the comparism of the activation energy of biodiesels from soyabeansoapstock and palm oil feedstocks with similar percentage of saturates $(51 \%)$. The activation energy of transesterification reaction between palm oil and methanol under subcritical conditions was $105 \mathrm{KJ} / \mathrm{mol}$ [16]. This was significantly higher than that of soyabeansoapstock stated above $(74 \mathrm{KJ} / \mathrm{mol})$ because of the effect of catalyst and/or co-solvent used in the reaction. Encar et al, [4] further reiterated this opinion by stating that low activation energies could be as a result of catalytic activities of the catalysts used in the course of the reaction.

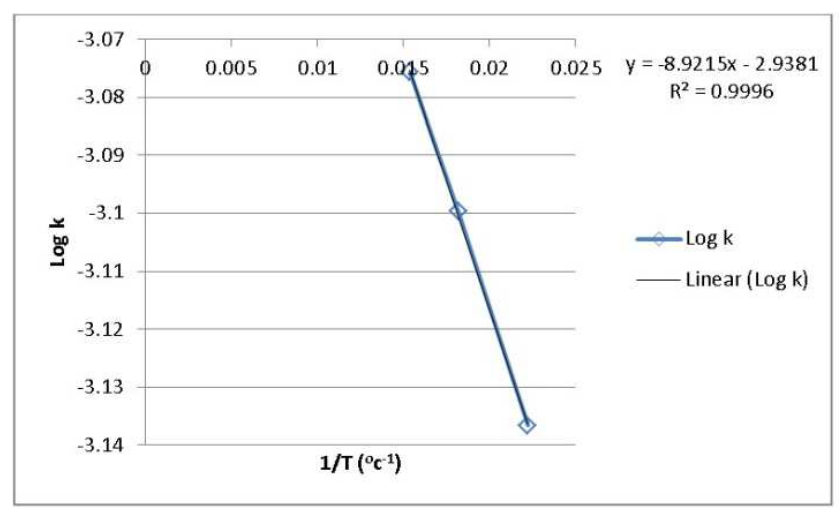

Figure 5. Plot of $\log k$ vs $1 / T$ esterifiation reversible models for soyabeansoapstock.

\section{Conclusion and Recommendation}

\subsection{Conclusion}

It can be concluded from this work that soyabeansoapstock is a good and viable feedstock for the production of biodiesel. The use of n-hexane as a co-solvent however greatly improved the yield obtained during transesterification of soyabeansoapstock with a yield of $96.8 \%$ obtained at an optimum reaction temperature of $55^{\circ} \mathrm{C}$. The rate determining steps met the reaction order and rate determining step requirements of both reversible and irreversiblemethanolysis reaction of the soyabeansoapstock with a reaction rate and order of $0.0008 \mathrm{~min}^{-1}$ and 2 obtained respectively. The activation energy needed for the reaction to take place was 74 $\mathrm{KJ} / \mathrm{mol}$ which falls within range of activation energies needed for transesterification of saturated oils.

\subsection{Recommendation}

The use of effluents from industrial processes such as soapstocks from vegetable oil processing plants should be looked into as a way of sourcing cheaper feedstock for biodiesel production.

Improved yields could be obtained by deviating from conventional transesterification procedures such as in this case, introduction of co-solventsand in some cases use of alternative catalysts and/or solvents.

Greater emphasis should be placed on the choice of temperatures in transesterification reactions as it influences rate of reactions and yield.

\section{References}

[1] Baskar, T., Pravin, R. S., Bagavathi, M., Srinivasan, R \& Lin, L (2019). Catalysis in biodiesel production - a review. Clean Energy. 3 (1): pp 2-23.

[2] Choudhury, H. A., Srivastava, P \&Moholkar, V. S (2014). Single-step ultrasonic synthesis of biodiesel from crude Jatrophacuraes oil. American Institute of Chemical Engineers Journal. 60: pp 1572-1581.

[3] Darnoko, D \& Cheryan, M (2000). Journal of the American Oil Chemists' Society. 77 (12): pp 1263.

[4] Encinar, J. M., Pardal, A \& Sanchez, N. (2016). An improvement to the transesterification process by the use of co-solvents to produce biodiesel fuel. 60: pp 1572-1581.

[5] Esonye, C., Onukwuli, O. D \& Ofoefule, A. U (2019). Optimization of methyl ester production from Prunus Amygdalus seed oil using response surface methodology and artificial neural networks. Renewable Energy. 130: pp 61-72.

[6] Esonye, C., Onukwuli, O. D \& Ofoefule, A. U (2019). Chemical kinetics of a two-step transesterification of dyacrodesedulis seed oil using acid-alkali catalyst. Chemical Engineering Research and Design. 145: pp 245-257.

[7] Faruque, M. O., Razzak, S. A \&Hossain, M. M. (2020). Application of heterogenous catalysts for biodiesel production from microalgal oil. Catalysts. 10 (25): pp 1-25.

[8] Furyta, S., Matsuhashi, H., Arata, K. (2004) Catalysis Communications. 5 (721).

[9] Ramadhas, A. S., Jayaraj, S \&Muraleedharan, C. (2005). Biodiesel production from high FFA rubber seed oil. Fuel. 84 (4): pp 335-340. 
[10] Ganesan, D., Rajendran, A. \&Thangavelu, V (2009). An overview on the recent advances in the transesterification of vegetable oils for biodiesel production using chemical and biocatalysts. Rev Environ SciBiotechnol. 8: pp 367.

[11] Hoda, N. (2010). Optimization of biodiesel production from cottonseed oil by transesterification using $\mathrm{NaOH}$ and methanol. Energy Sources, Part A: Recovery, Utilization, and Environmental Effects. 32 (5): pp 434-441.

[12] Ling, Gu., Wei, H., Shaokun, T., Songjiang, T \& Xiangwen, Z (2015). A novel deep eutectic solvent for biodiesel preparation using a homogenous base catalyst. Chemical Engineering journal. 259: pp 647-652.

[13] Ma, F., Hanna, M. A (1999) Biodiesel Production: AReview. Bioresour Technol. 70: pp 1-15.

[14] Noureddini, H \&Zhu, D. (1997). Kinetics of transesterification of soybean oil. J. Am. Oil Chem. Soc. 74: pp 1457-1463.
[15] Patil, P., Gude, V. G., Pinappu, S \& Deng, S (2011). Transesterification kinetics of camelina sativa oil on metal oxide catalysts under conventional and microwave heating conditions. Chemical Engineering Journal. 168: pp 1296-1300.

[16] Permsuwan, A., Tippayawong, N., Tanongkiata, T., Thararux, C \&Wangkarn J. (2011). Reaction kinetics of transesterification between palm oil and methanol under subcritical conditions. Energy. Technol. 2: pp 35-42.

[17] Singh, A. K., Fernando, S. D (2007). Reaction Kinetics of Soybean Oil Transesterification Using Heterogeneous Metal Oxide Catalysts. Chem. Eng. Technol. 30 (12): pp 1716-1720.

[18] Vicent, G., Coteron, A., Martinez, M., Aracil, J., (2009) Indusrial Crops and Products. Fuel. 8 (29): pp 88. 